\title{
A Review of Cognitive Disorders in Attention Deficit Hyperactivity Disorder with Emphasis on Executive Functions and Brain Structures
}

\author{
Somayeh Roshannia ${ }^{1}$, Somayeh Maleki-Karamolah ${ }^{2}$, Zhamak Akhlaghi ${ }^{3}$, Parastou Kordestani-Moghadam ${ }^{*}$ \\ ${ }^{1}$ Department of Psychology, Lorestan University, Khorramabad, Iran \\ ${ }^{2}$ Department of Psychology, Faculty of Humanities and Social Sciences, University of Kurdistan, Sanandaj, Iran \\ ${ }^{3}$ Cognitive Neuroscience Department, Institute for Cognitive Science Studies (ICSS), Tehran, Iran \\ ${ }^{4}$ Social Determinants of Health Research Center, Lorestan University of Medical Sciences, Khorramabad, Iran
}

\begin{abstract}
Attention deficit hyperactivity disorder (ADHD) is one of the most common childhood neurodevelopmental disorders characterized by levels of attention deficit disorder, irregularity, or hyperactivity/impulsivity. Studies have shown that only a fraction of children with ADHD, and not all of them, suffer from performance-related impairments. However, recently it has become clear that all people with this disorder are impaired in executive functions (EFs). In other words, ADHD is fundamentally a developmental disorder of EFs. Poor inhibitory control, continuous attention deficit, problem-solving, and behavioral inhibition are cognitive deficits in children with ADHD, and can be seen in tests related to EFs. Evidence suggests differences in some EFs, such as behavioral inhibition between boys and girls. ADHD has its neurobiological basis and most empirical evidence indicates delayed frontal lobe development in children with this disorder. Therefore, we aimed to review cognitive disorders in children with ADHD with an emphasis on EFs.

Keywords: Executive function; Attention deficit hyperactivity disorder; Children; Cognitive function.
\end{abstract}

*Correspondence to Parastou KordestaniMoghadam,

Social Determinants of Health Research Center, Lorestan

University of Medical Sciences, Khorramabad, Iran; P.O. Box: 6814993165; Tel: 06633120140; Fax: 06633120140,

Email: kordestani.p@lums.ac.ir

Published online March 27 2021

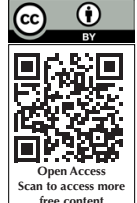

Citation: Roshannia S, Maleki-Karamolah S, Akhlaghi Z, Kordestani-Moghadam P. A review of cognitive disorders in attention deficit hyperactivity disorder with emphasis on executive functions and brain structures. Clin Neurosci J. 2021;8(2):60-66. doi:10.34172 icnj.2021.14

\section{Introduction}

Attention deficit hyperactivity disorder (ADHD) is a common neurodevelopmental disorder in children whose symptoms were first described by Heinrich Hoffmann in $1863 .{ }^{1}$ It is characterized by disruption of inattention, conduct disorder, poor social communication, and hyperactivity/impulsivity. Inattention causes an inability to remain focused on schoolwork, seeming not to listen, and losing things at school more frequently than what is consistent with the child's developmental level. Hyperactivity and impulsivity, on the other hand, result in excess activity, fidgeting, trouble remaining seated, disturbing others' activities, and trouble waiting for one's turn. ${ }^{2,3}$ ADHD tends to overlap with other common externalizing disorders in children, such as oppositional disorder and conduct disorder. ${ }^{4,5}$ If the condition persists until adulthood, it often leads to social performance deficit as well as educational and professional dysfunctions. ${ }^{6}$ Although hyperactivity subsides with age, attention deficit increases in most patients. ${ }^{7}$

In most cultures, demographic surveys report a prevalence of nearly $5 \%$ and $2.5 \%$ in children and adults, respectively. ${ }^{8}$ Overall, the disorder affects boys more than girls, with
$1.2 \%$ and $1.6 \%$ higher occurrence during childhood and adulthood, respectively. However, girls are more prone to displaying inattention symptoms. ${ }^{9}$ Evidence from various studies in neuropsychology, ${ }^{10}$ pathophysiology, ${ }^{11}$ genetics, ${ }^{12}$ and phenotypes, ${ }^{13}$ suggest that several factors with varying levels of intensity manifest clinically as attention deficit and hyperactivity.

Since the 1970s, numerous studies have identified impairments in executive functioning as the core cause of ADHD in adolescents. ${ }^{14}$ These impairments lead to deficits in essential cognitive abilities for complex goaloriented behaviors and adjusting to a range of changes and environmental demands. ${ }^{9}$ several authors ${ }^{15,16}$ believed that some, but not all, children with ADHD suffer from significant impairments in several areas of executive functioning; however, other authors such as Brown ${ }^{17}$ discussed that ADHD is fundamentally a developmental disorder that affects executive functions (EFs) in all cases. Thus, this paper focuses exclusively on this issue.

The aim of this study is to review existing research on cognitive impairments in children with ADHD with a focus on EFs.

(C) 2021 The Author(s). This is an open access article distributed under the terms of the Creative Commons Attribution License (http:// creativecommons.org/licenses/by/4.0/), which permits unrestricted use, distribution, and reproduction in any medium, provided the original work is properly cited. 


\section{Executive Functions}

EFs, also known as executive control or cognitive control, are a complex set of interrelated cognitive processes controlled through neural activity. ${ }^{18}$ EFs enable various forms of dynamic behavior that are essential for goaloriented behaviors such as problem-solving, behavioral control, attention, learning, decision-making, planning, and behavior regulation in new situations. ${ }^{19}$

The term executive function was coined by Lezak, but first described by Luria, who proposed a three functional unit model of the brain based on clinical findings: (1) arousalmotivation (limbic and reticular systems); (2) obtaining, processing, integrating, and storing information (cortical areas); and (3) planning, controlling, and verifying activity (depending on the activity of the prefrontal cortex). ${ }^{20}$ These complex components act based on hierarchical and functional areas and collaborate to regulate all behaviors and mental processes. ${ }^{21}$

Based on a categorization of EFs, inhibition can be divided into inhibitory control (which includes selfinhibitory behavior, interference control, selective attention, and cognitive inhibition), working memory, cognitive flexibility is also known as mental flexibility, ${ }^{22}$ reasoning, problem-solving, and planning. ${ }^{23}$

Fuster $^{24}$ is a widely-recognized authority on EF, who proposed a general theory on the role of EF in cortical regions and the significance of these regions in the temporary nature of behavior. EFs are indeed cognitive abilities that organize behavior and cognition into goaldirected structures of action. Moreover, cognitive abilities partly follow EF, for example, attention (vigilance, sustained attention, spatial attention, and control interference), memory, working memory, decisionmaking, and inhibitory control.

Recently, researchers have reached a consensus on the building blocks of EF: (1) working memory, (2) cognitive flexibility, and (3) preventing potential impulses. ${ }^{18,25}$

\section{Executive Function and Gender}

In the context of $\mathrm{ADHD}$, gender differences have received little research attention. ${ }^{26,27}$ Nevertheless, boys with ADHD score lower on verbal memory scales compared to their non-ADHD counterparts. No significant differences are observed among ADHD subgroups. Boys with ADHD also display impairments in intervention control, response inhibition, designing and planning. However, after controlling for age, intelligence quotient (IQ), and measures irrelevant to $\mathrm{EF}$, the functional impairments disappeared. ${ }^{16}$

A recent study compared EF in boys with ADHD, girls with $\mathrm{ADHD}$, and a control group using rapid naming, processing speed, memory, inhibition, interferences, and the Conner's rating scales. According to the results, boys and girls with ADHD performed similarly, with boys displaying more extensive impairments in terms of inhibition. Moreover, after controlling for IQ, reading ability, and comorbidities, those with ADHD exhibited a severe deficit in terms of naming speed, processing ability, and inhibition. ${ }^{28}$

\section{Neuroanatomy of Executive Function}

EFs are closely linked to frontal lobe activity. At a clinicalanatomic level, it is significantly related to evidence from patient reports after brain injuries that lead to executive dysfunction or frontal lobe dysfunction. ${ }^{19,29}$

Recent developments in imaging (e.g., MRI, fMRI, and positron emission tomography) have shown that EFs are linked to several networks ${ }^{19}$ in both the cortical and subcortical regions. ${ }^{30}$

In human and non-human primates, the frontal lobe consists of the dorsolateral prefrontal cortex, cingulate, posteromedial, and frontomedial cortex. These regions are involved in complex cognitive processes. For instance, the posterior regions are related to the working memory area, the anterior and medial regions in motivation, and the orbital region in impulse inhibition and interference. ${ }^{31}$

Emphasizing the role of cortical orbits, several authors claim that the dorsolateral orbits play a role in information organization for response facilitation. The anterior cingulate cortex is related to motivation and the ventromedial prefrontal cortex translates limbic and emotional information into behavioral responses. For instance, these authors believe that EF impairments, which lead to impulsivity and lack of appetite, indicate dysfunction in the subcortical orbit. ${ }^{32}$ Moreover, it should be noted that, although EFs are closely linked to the cortical region, they are not entirely reliant on it; they also depend on the cortical dopaminergic striatum system. ${ }^{29}$ This is the neurobiological foundation of EF which acts as a place to coordinate different functions because it can receive information from all sensory and motor systems in the brain. ${ }^{33}$

Bonelli and Cummings ${ }^{32}$ reported that the neuropsychiatric expression associated with progressive diseases is closely related to damage to neurological orbits stemming from the frontal lobe to other regions of the brain, especially the subcortical regions because effective mechanisms allow organisms to act efficiently in a chaotic environment. These findings are supported by the connection between religious beliefs, psychological injuries, and behavioral disorders. ${ }^{34}$

Numerous neurodevelopmental disorders are associated with changes in EF that are similar to those identified in people with frontal lobe damage, including sustained and selective attention, irritability, hyperactivity, attention deficit, working memory, three inhibitory mechanisms (patience, impulse, and interference control), selfregulation, cognitive inflexibility, and difficulty planning. ${ }^{21}$ Despite the lack of consensus regarding the role of EF impairments in ADHD, some studies suggest that other 
regions of the brain which cause impairments in functions that are unrelated to EF and the prefrontal cortex of the brain. These include short-term visual memory which depends on the health of the temporal lobe, the amygdala, and the hippocampus ${ }^{35}$ as well as tasks that are principally related to parietal functioning. ${ }^{36}$

\section{Neuroimaging in ADHD}

In the neuroimaging studies, patients with ADHD have shown abnormal activities during EF tasks. ${ }^{37}$

Previous studies with task-based functional magnetic resonance imaging (fMRI) and positron emission tomography (PET) revealed that working memory processing which relates to brain regions involving the prefrontal cortex and caudate nucleus had reduced in both children and adults with $\mathrm{ADHD},{ }^{38}$ also resting-state fMRI studies were demonstrated that strong functional connectivity in frontostriatal has a positive correlation with $\mathrm{EF}$, especially in inhibitory response and working memory in patients with ADHD. ${ }^{19,39}$ PET study also revealed that patients with $\mathrm{ADHD}$ have norepinephrine transporters in subcortical regions similar to healthy individuals. $^{40}$

\section{Cognitive Disorders in ADHD}

Impairment in EFs is a crucial cognitive consequence caused by ADHD. In addition, it cannot be diagnosed by cognitive issues alone; rather, it is identified by the changes in emotional levels such as cognition, regulation, and emotional expression ${ }^{7}$ that is caused by deficits in the executive control procedures ${ }^{2}$ and may have long-term effects on the growth and performance of the person.

The consequences of ADHD are analyzed using neurocognitive and cognitive instruments. Moreover, their efficacy has been shown with the help of multiple neurological tests, neurocognitive experiments and neural imaging, or electroencephalogram. Recently, the studies about mental action tools in people with ADHD have shown the difference of mental activity patterns between children with ADHD and other children by evaluating electrophysiology variables such as reaction time in go/no go cognitive tasks, ${ }^{41}$ inhibitory control tasks, ${ }^{42}$ and facing emotional stimulus.

Research has identified numerous cognitive impairments in EF, such as memory and perception, among children with ADHD. ${ }^{43}$ Therefore, impairments in ADHD are derived from disorders of frontal lobe performance and especially the prefrontal cortex, which primarily causes delay or mitigation in EFs; a crucial requirement for successful transformation in different cognitive procedures to achieve certain goals. ${ }^{44}$

Consequently, changes in the prefrontal cortex in people with ADHD, who usually suffer from syndromes related to executive control disorders, typically result in inhibitory issues inactive memory, and planning ${ }^{15}$ as well as efficiency, creativity and inability to abstract ideation and prediction of conduct consequences which will, in turn, lead to higher impulsivity ${ }^{43}$ Furthermore, patients with ADHD have significant trouble with balancing, identifying, and understanding emotions, which results in an increase in agitation, irritability, and frustration levels. ${ }^{45}$

In summary, $\mathrm{ADHD}$ has specific cognitive and neural foundations. Observations show that frontal lobe development is delayed in these children, which leads to EF impairments. ${ }^{8}$ These deficits are a basis for ADHD symptoms, which manifest in the society and school. ${ }^{46}$ In the following sections, some of the most significant EFs that are impaired in children with ADHD are briefly reviewed.

\section{Inhibitory Control}

Inhibitory control or inability to inhibit reactions to distracting stimulants is one of the EFs observed in children with ADHD. ${ }^{47}$ According to Barkley, ${ }^{8}$ problems referring to attention maintenance in $\mathrm{ADHD}$ are caused by hypo-function of the inhibitory behavior system, especially poor interference control. Based on Barkley's model, ${ }^{8}$ impairments in inhibitory behavior include delays or disorders in the development of four neurocognitive functions: (1) nonverbal memory, (2) verbal working memory, (3) emotional self-regulation, and (4) reconstruction. The most important constituent of this model is inhibitory behavior that provides a foundation for neurocognitive skills. Another constituent is motor control that is directly linked to the previous constituent and intermediates the four aforementioned EFs, which control behavior. ${ }^{48}$

Accordingly, Nigg et $\mathrm{al}^{49}$ have confirmed disorder in different forms of executive inhibitory responses. However, there are doubts about whether ADHD is caused by a primary or secondary inhibitory disorder. As stated by Nigg et al, ${ }^{49}$ although studies show consistent results in terms of impulsivity and disturbing behavior, the concept of inhibition should be thoroughly conceptualized to identify the differences between stimulating control, executive control, and stimulating inhibitory control.

ADHD is correlated with weak cognitive control and especially inhibitory control, ${ }^{50}$ which can explain why children with ADHD tend to have slower reaction times in comparison to normal children. In response to this question, researchers have argued that these children need more time for potential inhibition of their reactions. ${ }^{51}$ An inhibitory deficit in ADHD is linked to executive and structural abnormalities in basic brain circuits, which is often an indicator of deficit in cortical tasks, ${ }^{52-54}$ found that symptoms of ADHD include poor functions in neuropsychological inhibitory instruments (unpredictability, loss of insight, poor organization, difficulty understanding time and overreaction). 
Several studies about children with ADHD have shown that changes in attention, and inhibitory control lead to poor self-regulation and behavioral issues. ${ }^{55}$ These findings support the idea of multipurpose location systems in these disorders (for example anterior and posterior cortex, striatum, thalamus, and the limbic system which are connected to neurotransmitter systems). ${ }^{8}$

Lack of inhibitory control in ADHD is not only linked to behavioral and cognitive impairment but also related to emotional turmoil. Although impaired emotion regulation is not a sign of $\mathrm{ADHD}$, it is a fundamental aspect of this disorder. ${ }^{8}$ Children with ADHD often show symptoms such as irritability, bad temper, intolerance toward frustration, and sudden, unpredictable outbursts of negative emotions such as anger and unhappiness. ${ }^{7}$ This can explain impaired emotion regulation based on control impairment. Empirical observations have shown that children with ADHD not only suffer from attention deficit, irregular conduct, hyperactivity, and irritability, but also have different emotional problems such as emotional responsibility, extreme emotional reaction, and irritability. ${ }^{56}$ Emotional self-regulation balances the emotions; however, in case of dysfunction, it can lead to more intense emotional reactions as well as lower sympathy and ability to regulate emotional states. ${ }^{8}$ Therefore, children with ADHD experience several problems relating to emotional expression, which arise from dysfunction in inhibitory control processes. ${ }^{48}$

\section{Attention}

Attention deficit is observed in the academic, social, cognitive, and emotional performance of many students with ADHD. ${ }^{57}$ Children with this disorder might not be able to precisely focus on the details or may exhibit careless mistakes in their school tasks or other activities. Their activities are often irregular and done without reflection. Maintaining attention is often difficult for these children, and they can hardly show stability to finish their homework, because they may switch from one incomplete activity to another. Children who are diagnosed with ADHD may switch from one task to another without ever finishing anything. They often have trouble regulating their tasks or activities. ${ }^{55}$ The most significant problem in children with ADHD involves attention. Consistent attention allows a person to focus on just one stimulus and ignore interferences. ${ }^{58}$ As mentioned by Barkley ${ }^{8}$ controlling these interferences is a kind of consistent attention and a behavioral inhibitory function. The problem these children have with attention is caused by the interaction between behavioral inhibition and EFs.

\section{Behavioral Inhibition}

EF deficits in ADHD involve inhibiting or stopping behavior. $^{59}$ These deficits, especially inhibitory behavior, which is known as an executive skill that evolved during childhood, are at the center of ADHD and have been the subject of many studies. ${ }^{60}$ As an example, in a study of children with $\mathrm{ADHD}$ and children with reading disabilities, those who have ADHD, with and without comorbid learning disabilities, showed impairments in the speed of processing, naming objects, inhibitory behavior, and had variability in reaction time. In contrast, those with a learning disability as well as patients with ADHD with a dominant learning disability had deficits in working verbal memory and slow speed of retrieval. The study used regression analysis to identify variability in response time and naming incongruent colors in the Stroop test as the best predictors of hyperactivity and impulsivity in ADHD. Deficits related to naming objects and inhibitory control were exclusive to those with learning disabilities and ADHD, respectively. ${ }^{61}$ Other studies confirm that children with learning disabilities or ADHD exhibit more significant impairments in both executive and non-EFs compared to the control group, especially with mathematics. ${ }^{48}$

Inhibitory control is needed in situations in which an ongoing activity or thought must be stopped promptly, and the child should be able to ignore the information on which he/she does not want to focus. Barkley ${ }^{8}$ states that children with ADHD have significant impairments in inhibitory behavior, which leads to EF deficits. Compared to their normal peers, these children are less likely to separate emotional elements of environmental messages from informational elements, use providence and reconsideration to control their behavior, use inner speech to guide their behavior, and analyze or link the different aspects of their environment. ${ }^{49}$ There is a consensus on the organizational role of EF. ${ }^{15}$ which controls behavioral responses such as the ability to control and inhibit stimuli, planning, flexibility, and organization, using working memory, problem-solving, and objectively doing school assignments. ${ }^{62}$

Inhibitory behavior issues in children with $\mathrm{ADHD}$ may lead to problems in their education, including weak academic performance, lack of motivation, learning disabilities, carelessness, low self-esteem, aggressiveness, distraction, arousal (excitation), and poor communications with their peers. EF deficiencies cause major problems for children in their school assignments. Therefore, the attention deficit component of ADHD is the consequence of an impairment that results from inhibitory control and weak interference in executive control of behavior. ${ }^{63}$

\section{Problem-Solving}

Some authors report impairments in problem-solving and other cognitive processes associated with poor academic performance among children with ADHD. For example, ADHD students tend to perform poorly in math 
compared to their normal counterparts. ${ }^{64}$

\section{Discussion and Conclusion}

Based on the preceding review of literature, as one of the most common neurodevelopmental disorders, $\mathrm{ADHD}$ is characterized by disruptive levels of inattention, irregularity, and hyperactivity/impulsivity. ${ }^{47}$ Evidence suggests that ADHD may be caused by EF deficits. ${ }^{65}$ Furthermore, these children show numerous impairments in tests of EF. ${ }^{66}$ For example, poor cognitive control, especially inhibitory control or inability to ignore distracting stimuli, is typically observed in children with ADHD. ${ }^{67}$ Inability to maintain attention or remain vigilant while doing tasks is another problem in ADHD students. ${ }^{68}$ Difficulty in problem-solving and other cognitive processes that are associated with reduced academic performance are also linked to ADHD. ${ }^{69} \mathrm{EF}$ deficits in ADHD involve inhibiting or stopping behavior. These impairments, especially inhibitory behavior, which is known as an executive skill evolved during childhood, are at the center of ADHD. ${ }^{70}$

Although a few neuropsychological studies have reviewed gender differences, boys and girls have been found to exhibit differences in EFs. ${ }^{71}$ ADHD has a specific neurobiological basis, ${ }^{72}$ and most extant evidence indicates a delay in cortical lobe formation of children with $\mathrm{ADHD}$, which leads to impairments in $\mathrm{EF}^{73}$ However, recent studies have shown that EFs are linked to several networks. ${ }^{74}$

Thus, future work should mainly focus on potential gender differences between different EFs in ADHD. Moreover, topics about the relationship between neuropsychological mechanisms and EFs or the relationship between cognitive functions with this group of EFs, particularly inhibitory behavior, can make the basis for future research.

\section{Conflict of Interest}

The authors declare that they have no conflict of interests.

\section{Acknowledgments}

This research has not received any financial support from any institution

\section{Ethical Statement}

Not applicable.

\section{References}

1. Freckelton I. Attention deficit hyperactivity disorder (ADHD) and the criminal law. Psychiatr Psychol Law. 2019;26(6):81740. doi: 10.1080/13218719.2019.1695266.

2. American Psychiatric Association (APA). Diagnostic and Statistical Manual of Mental Disorders (DSM-5). APA; 2013. p. 21.

3. Silverstein MJ, Faraone SV, Leon TL, Biederman J, Spencer TJ, Adler LA. The relationship between executive function deficits and DSM-5-defined ADHD symptoms. J Atten Disord. 2020;24(1):41-51. doi: 10.1177/1087054718804347.
4. Davids E, Gastpar M. Attention deficit hyperactivity disorder and borderline personality disorder. Prog Neuropsychopharmacol Biol Psychiatry. 2005;29(6):865-77. doi: 10.1016/j.pnpbp.2005.04.033.

5. Bendiksen B, Aase H, Diep LM, Svensson E, Friis S, Zeiner P. The associations between pre- and postnatal maternal symptoms of distress and preschooler's symptoms of ADHD, oppositional defiant disorder, conduct disorder, and anxiety. J Atten Disord. 2020;24(7):1057-69. doi: 10.1177/1087054715616185.

6. Ranby KW, Boynton MH, Kollins SH, McClernon FJ, Yang C, Fuemmeler BF. Understanding the phenotypic structure of adult retrospective ADHD symptoms during childhood in the United States. J Clin Child Adolesc Psychol. 2012;41(3):26174. doi: 10.1080/15374416.2012.654465.

7. Sobanski E, Banaschewski T, Asherson P, Buitelaar J, Chen W, Franke B, et al. Emotional lability in children and adolescents with attention deficit/hyperactivity disorder (ADHD): clinical correlates and familial prevalence. J Child Psychol Psychiatry. 2010;51(8):915-23. doi: 10.1111/j.1469-7610.2010.02217.x.

8. Barkley RA. Attention-Deficit Hyperactivity Disorder. Guilford Publications; 2006.

9. Brock SE, Jimerson SR, Hansen RL. Identifying, Assessing, and Treating ADHD at School. Springer; 2009.

10. Solanto MV, Abikoff H, Sonuga-Barke E, Schachar R, Logan GD, Wigal T, et al. The ecological validity of delay aversion and response inhibition as measures of impulsivity in AD/ HD: a supplement to the NIMH multimodal treatment study of AD/HD. J Abnorm Child Psychol. 2001;29(3):215-28. doi: 10.1023/a:1010329714819.

11. Rothenberger $A$, Banaschewski $T$, Heinrich $H$, Moll GH, Schmidt MH, van't Klooster B. Comorbidity in ADHD-children: effects of coexisting conduct disorder or tic disorder on eventrelated brain potentials in an auditory selective-attention task. Eur Arch Psychiatry Clin Neurosci. 2000;250(2):101-10. doi: 10.1007/s004060070042.

12. Nadder TS, Rutter M, Silberg JL, Maes HH, Eaves LJ. Genetic effects on the variation and covariation of attention deficithyperactivity disorder (ADHD) and oppositional-defiant disorder/conduct disorder (Odd/CD) symptomatologies across informant and occasion of measurement. Psychol Med. 2002;32(1):39-53. doi: 10.1017/s0033291701004792.

13. Coxe S, Sibley MH, Becker SP. Presenting problem profiles for adolescents with ADHD: differences by sex, age, race, and family adversity. Child Adolesc Ment Health. 2020. doi: 10.1111/camh.12441.

14. Goldstein S, Naglieri JA. The school neuropsychology of ADHD: theory, assessment, and intervention. Psychol Sch. 2008;45(9):859-74. doi: 10.1002/pits.20331.

15. Willcutt EG, Doyle AE, Nigg JT, Faraone SV, Pennington BF. Validity of the executive function theory of attention-deficit/ hyperactivity disorder: a meta-analytic review. Biol Psychiatry. 2005;57(11):1336-46. doi: 10.1016/j.biopsych.2005.02.006.

16. Scheres A, Oosterlaan J, Geurts H, Morein-Zamir S, Meiran $\mathrm{N}$, Schut $\mathrm{H}$, et al. Executive functioning in boys with ADHD: primarily an inhibition deficit? Arch Clin Neuropsychol. 2004;19(4):569-94. doi: 10.1016/j.acn.2003.08.005.

17. Brown TE. Executive functions and attention deficit hyperactivity disorder: implications of two conflicting views. Intl J Disabil Dev Educ. 2006;53(1):35-46. doi: 10.1080/10349120500510024

18. Diamond A. Executive functions. Annu Rev Psychol. 2013;64:135-68. doi: 10.1146/annurev- 
psych-113011-143750.

19. Chung HJ, Weyandt LL, Swentosky A. The physiology of executive functioning. In: Handbook of Executive Functioning. New York, NY: Springer; 2014. p. 13-27.

20. Ardila A. On the evolutionary origins of executive functions. Brain Cogn. 2008;68(1):92-9. doi: 10.1016/j. bandc.2008.03.003.

21. Jurado $M B$, Rosselli $M$. The elusive nature of executive functions: a review of our current understanding. Neuropsychol Rev. 2007;17(3):213-33. doi: 10.1007/s11065007-9040-z.

22. Miyake A, Friedman NP, Emerson MJ, Witzki AH, Howerter A, Wager TD. The unity and diversity of executive functions and their contributions to complex "Frontal Lobe" tasks: a latent variable analysis. Cogn Psychol. 2000;41(1):49-100. doi: 10.1006/cogp.1999.0734.

23. Collins A, Koechlin E. Reasoning, learning, and creativity: frontal lobe function and human decision-making. PLoS Biol. 2012;10(3):e1001293. doi: 10.1371/journal.pbio.1001293.

24. Fuster JM. The prefrontal cortex in the neurology clinic. Handb Clin Neurol. 2019;163:3-15. doi: 10.1016/b978-012-804281-6.00001-x.

25. Hofmann W, Schmeichel BJ, Baddeley AD. Executive functions and self-regulation. Trends Cogn Sci. 2012;16(3):174-80. doi: 10.1016/j.tics.2012.01.006

26. Doyle AE, Biederman J, Seidman LJ, Weber W, Faraone SV. Diagnostic efficiency of neuropsychological test scores for discriminating boys with and without attention deficithyperactivity disorder. J Consult Clin Psychol. 2000;68(3):47788. doi: 10.1037/0022-006x.68.3.477.

27. Doyle AE. Executive functions in attention-deficit/hyperactivity disorder. J Clin Psychiatry. 2006;67 Suppl 8:21-6.

28. Rucklidge JJ. Gender differences in neuropsychological functioning of New Zealand adolescents with and without attention deficit hyperactivity disorder. Intl J Disabil Dev Educ. 2006;53(1):47-66. doi: 10.1080/10349120600577402.

29. Elliott R. Executive functions and their disorders. Br Med Bull. 2003;65:49-59. doi: 10.1093/bmb/65.1.49.

30. Marvel CL, Desmond JE. Functional topography of the cerebellum in verbal working memory. Neuropsychol Rev. 2010;20(3):271-9. doi: 10.1007/s11065-010-9137-7.

31. FusterJM. Frontal lobeand cognitivedevelopment.J Neurocytol. 2002;31(3-5):373-85. doi: 10.1023/a:1024190429920.

32. Bonelli RM, Cummings JL. Frontal-subcortical circuitry and behavior. Dialogues Clin Neurosci. 2007;9(2):141-51. doi: 10.31887/DCNS.2007.9.2/rbonelli.

33. Arnsten AF, Li BM. Neurobiology of executive functions: catecholamine influences on prefrontal cortical functions. Biol Psychiatry. 2005;57(11):1377-84. doi: 10.1016/j. biopsych.2004.08.019.

34. Biederman J, Petty CR, Wozniak J, Wilens TE, Fried R, Doyle A, et al. Impact of executive function deficits in youth with bipolar I disorder: a controlled study. Psychiatry Res. 2011;186(1):58-64. doi: 10.1016/j.psychres.2010.08.029.

35. Giedd JN, Blumenthal J, Molloy E, Castellanos FX. Brain imaging of attention deficit/hyperactivity disorder. Ann N Y Acad Sci. 2001;931:33-49. doi: 10.1111/j.1749-6632.2001. tb05772.x.

36. Aman CJ, Roberts RJ, Pennington BF. A neuropsychological examination of the underlying deficit in attention deficit hyperactivity disorder: frontal lobe versus right parietal lobe theories. Dev Psychol. 1998;34(5):956-69. doi:
10.1037/0012-1649.34.5.956

37. Hart H, Radua J, Nakao T, Mataix-Cols D, Rubia K. Metaanalysis of functional magnetic resonance imaging studies of inhibition and attention in attention-deficit/hyperactivity disorder: exploring task-specific, stimulant medication, and age effects. JAMA Psychiatry. 2013;70(2):185-98. doi: 10.1001/jamapsychiatry.2013.277.

38. Roman-Urrestarazu A, Lindholm P, Moilanen I, Kiviniemi V, Miettunen J, Jääskeläinen $\mathrm{E}$, et al. Brain structural deficits and working memory fMRI dysfunction in young adults who were diagnosed with ADHD in adolescence. Eur Child Adolesc Psychiatry. 2016;25(5):529-38. doi: 10.1007/s00787-0150755-8.

39. Bollmann S, Ghisleni C, Poil SS, Martin E, Ball J, EichHöchli D, et al. Age-dependent and -independent changes in attention-deficit/hyperactivity disorder (ADHD) during spatial working memory performance. World J Biol Psychiatry. 2017;18(4):279-90. doi: 10.3109/15622975.2015.1112034.

40. Vanicek T, Spies M, Rami-Mark C, Savli M, Höflich A, Kranz GS, et al. The norepinephrine transporter in attention-deficit/ hyperactivity disorder investigated with positron emission tomography. JAMA Psychiatry. 2014;71(12):1340-9. doi: 10.1001/jamapsychiatry.2014.1226.

41. McLoughlin G, Palmer JA, Rijsdijk F, Makeig S. Genetic overlap between evoked frontocentral theta-band phase variability, reaction time variability, and attention-deficit/hyperactivity disorder symptoms in a twin study. Biol Psychiatry. 2014;75(3):238-47. doi: 10.1016/j.biopsych.2013.07.020.

42. Bruckmann S, Hauk D, Roessner V, Resch F, Freitag $\mathrm{CM}$, Kammer $\mathrm{T}$, et al. Cortical inhibition in attention deficit hyperactivity disorder: new insights from the electroencephalographic response to transcranial magnetic stimulation. Brain. 2012;135(Pt 7):2215-30. doi: 10.1093/ brain/aws071.

43. Arnett $A B$, Macdonald B, Pennington BF. Cognitive and behavioral indicators of ADHD symptoms prior to school age. J Child Psychol Psychiatry. 2013;54(12):1284-94. doi: 10.1111/jcpp.12104.

44. Funahashi S, Andreau JM. Prefrontal cortex and neural mechanisms of executive function. J Physiol Paris. 2013;107(6):471-82. doi: 10.1016/j.jphysparis.2013.05.001.

45. Martel MM, Nigg JT. Child ADHD and personality/temperament traits of reactive and effortful control, resiliency, and emotionality. J Child Psychol Psychiatry. 2006;47(11):117583. doi: 10.1111/j.1469-7610.2006.01629.x.

46. Gray SA, Chaban P, Martinussen R, Goldberg R, Gotlieb H, Kronitz R, et al. Effects of a computerized working memory training program on working memory, attention, and academics in adolescents with severe LD and comorbid ADHD: a randomized controlled trial. J Child Psychol Psychiatry. 2012;53(12):1277-84. doi: 10.1111/j.14697610.2012.02592.x.

47. Lange H, Buse J, Bender S, Siegert J, Knopf H, Roessner V. Accident proneness in children and adolescents affected by ADHD and the impact of medication. J Atten Disord. 2016;20(6):501-9. doi: 10.1177/1087054713518237.

48. Martínez L, Prada E, Satler C, Tavares MC, Tomaz C. Executive dysfunctions: the role in attention deficit hyperactivity and post-traumatic stress neuropsychiatric disorders. Front Psychol. 2016;7:1230. doi: 10.3389/fpsyg.2016.01230.

49. Nigg JT, Blaskey LG, Huang-Pollock CL, Rappley MD. Neuropsychological executive functions and DSM-IV ADHD 
subtypes. J Am Acad Child Adolesc Psychiatry. 2002;41(1):5966. doi: 10.1097/00004583-200201000-00012.

50. Chamberlain SR, Robbins TW, Winder-Rhodes S, Müller U, Sahakian BJ, Blackwell AD, et al. Translational approaches to frontostriatal dysfunction in attention-deficit/hyperactivity disorder using a computerized neuropsychological battery. Biol Psychiatry. 2011;69(12):1192-203. doi: 10.1016/j. biopsych.2010.08.019.

51. Shen IH, Tsai SY, Duann JR. Inhibition control and error processing in children with attention deficit/hyperactivity disorder: an event-related potentials study. Int J Psychophysiol. 2011;81(1):1-11. doi: 10.1016/j.ijpsycho.2011.03.015.

52. De La Fuente A, Xia S, Branch C, Li X. A review of attentiondeficit/hyperactivity disorder from the perspective of brain networks. Front Hum Neurosci. 2013;7:192. doi: 10.3389/ fnhum.2013.00192.

53. Hervey AS, Epstein JN, Curry JF, Tonev S, Eugene Arnold $\mathrm{L}$, Keith Conners C, et al. Reaction time distribution analysis of neuropsychological performance in an ADHD sample. Child Neuropsychol. 2006;12(2):125-40. doi: 10.1080/09297040500499081.

54. Tamm L, Narad ME, Antonini TN, O'Brien KM, Hawk LW Jr, Epstein JN. Reaction time variability in ADHD: a review. Neurotherapeutics. 2012;9(3):500-8. doi: 10.1007/s13311012-0138-5.

55. Puentes-Rozo PJ, Barceló-Martínez E, Pineda DA. [Behavioural and neuropsychological characteristics of children of both sexes, between 6 and 11 years of age, with attention deficit hyperactivity disorder]. Rev Neurol. 2008;47(4):175-84.

56. Schoemaker K, Bunte T, Wiebe SA, Espy KA, Deković $M$, Matthys W. Executive function deficits in preschool children with ADHD and DBD. J Child Psychol Psychiatry. 2012;53(2):111-9. doi: 10.1111/j.1469-7610.2011.02468.x.

57. McCloskey G, Perkins LA, Van Diviner B. Assessment and Intervention for Executive Function Difficulties. Taylor \& Francis; 2008.

58. Marzocchi GM, Ornaghi S, Barboglio S. What are the causes of the attention deficits observed in children with dyslexia? Child Neuropsychol. 2009;15(6):567-81. doi: 10.1080/09297040902740660.

59. Lacerda BC, Martínez SBS, Franz AP, Moreira-Maia CR, Silveira RC, Procianoy RS, et al. Does ADHD worsen inhibitory control in preschool children born very premature and/or with very low birth weight? Trends Psychiatry Psychother. 2020;42(4):340-7. doi: 10.1590/2237-6089-2019-0075.

60. Rucklidge JJ, Tannock R. Neuropsychological profiles of adolescents with ADHD: effects of reading difficulties and gender. J Child Psychol Psychiatry. 2002;43(8):988-1003. doi: 10.1111/1469-7610.00227.

61. Zambrano-Sánchez E, Martínez-Cortés JA, Rió-Carlos YD, Martínez-Wbaldo Mdel C, Poblano A. Executive dysfunction screening and intelectual coefficient measurement in children with attention deficit hyperactivity disorder. Arq Neuropsiquiatr. 2010;68(4):545-9. doi: 10.1590/s0004$282 \times 2010000400013$

62. Denckla MB. ADHD: topic update. Brain Dev. 2003;25(6):383-
9.

63. Manoli A, Liversedge SP, Sonuga-Barke EJS, Hadwin JA. The Differential Effect of Anxiety and ADHD Symptoms on Inhibitory Control and Sustained Attention for Threat Stimuli: A Go/No-Go Eye-Movement Study. J Atten Disord. 2020:1087054720930809. doi: 10.1177/1087054720930809.

64. Loe IM, Feldman HM. Academic and educational outcomes of children with ADHD. J Pediatr Psychol. 2007;32(6):643-54. doi: 10.1093/jpepsy/jsI054.

65. Savcı U, Tufan AE, Öztürk Y, Cansız MA. Executive function problems and treatment in children and adolescents with attention deficit and hyperactivity disorder. Psikiyatride Guncel Yaklasimlar. 2019;11(2):223-38.

66. Chang S, Yang L, Wang Y, Faraone SV. Shared polygenic risk for ADHD, executive dysfunction and other psychiatric disorders. Transl Psychiatry. 2020;10(1):182. doi: 10.1038/ s41398-020-00872-9.

67. Gooskens B, Bos DJ, Mensen VT, Shook DA, Bruchhage MMK, Naaijen J, et al. No evidence of differences in cognitive control in children with autism spectrum disorder or obsessive-compulsive disorder: an fMRI study. Dev Cogn Neurosci. 2019;36:100602. doi: 10.1016/j.den.2018.11.004.

68. Pievsky MA, McGrath RE. The neurocognitive profile of attention-deficit/hyperactivity disorder: a review of metaanalyses. Arch Clin Neuropsychol. 2018;33(2):143-57. doi: 10.1093/arclin/acx055.

69. Pila-Nemutandani RG, Meyer A. Behaviour planning and problem solving deficiencies in children with symptoms of attention deficit hyperactivity disorder from the Balobedu culture, Limpopo province, South Africa. J Child Adolesc Ment Health. 2016;28(2):109-21. doi: 10.2989/17280583.2016.1200582.

70. Chmielewski W, Bluschke A, Bodmer B, Wolff N, Roessner $\mathrm{V}$, Beste C. Evidence for an altered architecture and a hierarchical modulation of inhibitory control processes in ADHD. Dev Cogn Neurosci. 2019;36:100623. doi: 10.1016/j. dcn.2019.100623.

71. Barha CK, Davis JC, Falck RS, Nagamatsu LS, Liu-Ambrose T. Sex differences in exercise efficacy to improve cognition: a systematic review and meta-analysis of randomized controlled trials in older humans. Front Neuroendocrinol. 2017;46:71-85. doi: 10.1016/j.yfrne.2017.04.002.

72. Stevens MC, Pearlson GD, Calhoun VD, Bessette KL. Functional neuroimaging evidence for distinct neurobiological pathways in attention-deficit/hyperactivity disorder. Biol Psychiatry Cogn Neurosci Neuroimaging. 2018;3(8):675-85. doi: 10.1016/j.bpsc.2017.09.005.

73. Buchhorn R, Conzelmann A, Willaschek C, Störk D, Taurines $\mathrm{R}$, Renner TJ. Heart rate variability and methylphenidate in children with ADHD. Atten Defic Hyperact Disord. 2012;4(2):85-91. doi: 10.1007/s12402-012-0072-8.

74. Reineberg AE, Banich MT. Functional connectivity at rest is sensitive to individual differences in executive function: a network analysis. Hum Brain Mapp. 2016;37(8):2959-75. doi: 10.1002/hbm.23219. 